\title{
INCREMENTAL METHOD FOR UNLOADING PHENOMENON FIXATION AT SHAKEDOWN
}

\author{
Dovilè Merkevičiūtè, Juozas Atkoxiūnas \\ Dept of Structural Mechanics, Vilnius Gediminas Technical University, \\ Sauletekio al. 11, LT-2040 Vilnius, Lithuania \\ E-mail: dovile.merk@centras.lt; Juozas.Atkociunas@st.vtu.lt
}

Received 14 May 2003; accepted 19 June 2003

\begin{abstract}
Incremental method for shakedown analysis of the elastic perfectly plastic structures is based on the extremum energy principles and non-linear mathematical programming approach. Residual force increment calculation problem is developed applying minimum complementary deformation energy principle. The Rozen project gradient and equilibrium finite element methods were applied for solution. The Rozen optimality criterion (Kuhn-Tucker conditions) ensures compatibility of residual strains and allows plastic strain and residual displacement increment calculation without dual problem solution. The possibility to fix the structure cross-section unloading phenomenon during shakedown process was developed. The proposed technique is illustrated by annular bending plate residual force and deflection calculation examples, when the von Mises criterion is taken into account.
\end{abstract}

Keywords: shakedown, energy principles, mathematical programming, incremental analysis, unloading phenomenon.

\section{Introduction}

The elastic perfectly plastic structure is considered, the configuration, material, sandwich cross-section dimension of the structure and external load are prescribed. The structure adapted to the cyclic loading satisfies the constraints on strength and it is not likely to undergo cyclic plastic failure [1]. Nevertheless, in the shakedown structure some strains and deflections can appear which do not correspond to the maintenance conditions [2-6]. Hence in the mathematical models of optimization problems for shakedown structures both the strength and stiffness requirements must be taken into account [7-14] (Fig 1). When displacements are not restrained by stiffness conditions, the optimizing structure reaches the limit state related to cyclic-plastic failure.

In structural engineering the stiffness constraints are realized via the displacements (most deflections are constrained). Therefore for a structure under plastic behaviour prior to a cyclic-plastic failure it is necessary to know not only actual stresses but also strains and displacements (structural analysis problem) [15]. A large number of authors directly base their ideas on classical Melan and Koiter shakedown theorems [16] in the structural analysis problems. In this case mathematical programming is applied only as a tool for simple structures in solving the shakedown extremum problem. In the structural shakedown theory and practice every shakedown system under repeated load calculation technique and algorithms creation remains relevant. The quality of those algorithms results in a successful solution of the optimization problem.

In this paper the analysis of problems of dissipative structures (ie structures under plastic deformation) are formulated on the basis of the extremum energy principles characterising the actual structure stress-strain conditions $[8,9]$. Using non-linear programming theory, mathematical models of dual stress and strain analysis extremum problems of structure at shakedown are obtained (Fig 1, direct applications of mathematical programming duality theory for structure analysis at shakedown). Dual mathematical programming problems simu-

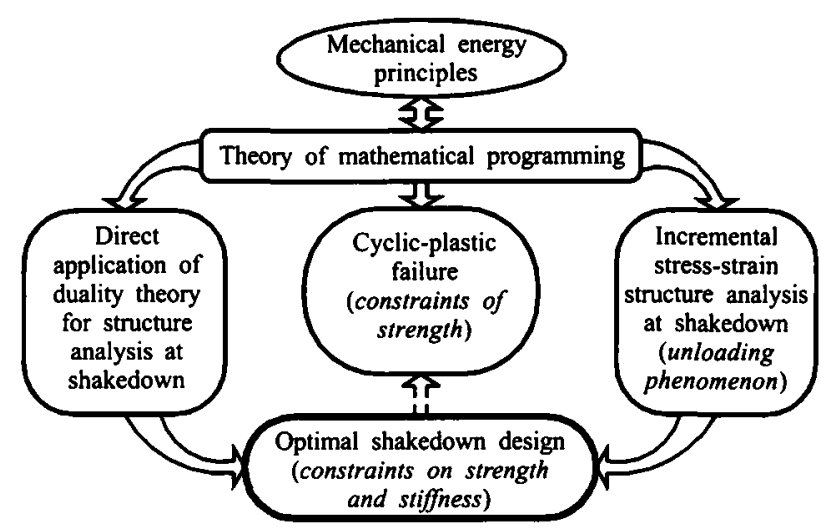

Fig 1. Connections between analysis and optimization problems 
late an actual behaviour of structure at shake-down only when there is not any unloading phenomenon in crosssections [17]. Applying the Rozen criterion [18] for incremental analysis problem solution, a new technique is created to determine unloading phenomenon in cross-sections during adaptation to quasi-static load process (Fig 1 , incremental stress-strain structure analysis at shakedown).

\section{Discrete definition of elastic-plastic structures}

Equilibrium finite element method [19-20] is applied for structure discretisation. Using this method more exact equilibrium equations are obtained to compare with other finite element methods. In company with it statically possible elastic $S_{e}$ (subscript $e$ ) and residual $S_{r}$ forces (total forces are denoted by $S=S_{e}+S_{r}$, displacements $-\mathbf{u}=\mathbf{u}_{e}+\mathbf{u}_{r}$ ) are defined more exactly. Structure discrete model degree of freedom is $m$, vectors of global displacements $u$ and load $F$ are $\mathbf{u}=\left(u_{1}, u_{2}, \ldots, u_{m}\right)^{T}$ and $\mathbf{F}=\left(F_{1}, F_{2}, \ldots, F_{m}\right)^{T}$ respectively. Force vector of element $k(k=1,2, \ldots, \eta$; $k \in K)$ with $\eta_{k}$ nodal points $\left(l=1,2, \ldots, \eta_{k}\right.$, $l \in L)$ is $S_{k}=\left(S_{k 1}, S_{k 2}, \ldots, S_{k l}, \ldots, S_{\eta_{k}}\right)^{T}$. The total component number of vector $S_{k}$ is $n_{k}$. Forces $S_{k}(x)$ at any point $x$ of finite element are expressed via forces $S_{k}$ of element nodal points using matrix of approximation $\mathbf{S}_{k}(\mathrm{x})=\left[N_{k}(\mathrm{x})\right] \mathbf{S}_{k}$. The equilibrium of discrete model is ensured only for structure elements and their main nodes [20]. Finally, taking into account boundary conditions, the structure equilibrium equations, system reads:

$$
[A] S=F \text { or } \sum_{k}\left[A_{k}\right] S_{k}=\mathbf{F},
$$

where $[A]$ is $m \times n$ the equilibrium matrix. The statically possible residual forces $S_{r}$ are self-balanced:

$$
[A] \mathbf{S}_{r}=0 \text {. }
$$

Geometric equations for structure discrete model read:

$$
[A]^{T} \mathbf{u}-[D] S=0 \text {. }
$$

Here $[D]=\operatorname{diag}\left[D_{k}\right]$ is the quasidiagonal structure flexibility matrix $(k \in K)$. Element flexibility matrix $\left[D_{k}\right]$ in the local coordinates is obtained applying the formula

$$
\left[D_{k}\right]=\int_{A_{k}}\left[N_{k}(\mathrm{x})\right]^{T}[\mathscr{Z}]\left[N_{k}(\mathrm{x})\right] d A, k \in K .
$$

The physical meaning of displacement vector u components is determined by equilibrium equations (1) formation order and dual relationship between equilibrium equations (1) and geometric ones (3). Applying the known finite elements procedures, elastic displacements $u_{e}$ and forces $S_{e}$ are obtained. Kinematically possible residual displacements $u_{r}$ satisfy geometric equations (3):

$$
[A]^{T} \mathbf{u}_{r}=\theta_{r}, \quad \theta_{r}=[D] \mathbf{s}_{r}+\theta_{p},
$$

where $\boldsymbol{\theta}_{p}$ is the vector of plastic strains. Residual strains $\theta_{r}$ and displacements $u_{r}$ can be non-unique: they depend on the particular loading history $F(t)$.

It is difficult to take into account loading history, when loading $F(t)$ is described via time $t$, independent load variation bounds $\mathbf{F}_{\text {sup }}$ and $\mathbf{F}_{\text {inf }}$ $\left(F_{\text {inf }} \leq \mathbf{F}(t) \leq F_{\text {sup }}\right)$. For instance, two loads $F_{1}(t)$, $F_{2}(t)$ variation field is shown as a dark quadrangle in Fig 2. Here the number of external force $\mathbf{F}_{\text {inf }}=\left(F_{1, \text { inf }}, F_{2, \text { inf }}\right)^{T}, \mathbf{F}_{\text {sup }}=\left(F_{1, \text { sup }}, F_{2, \text { sup }}\right)^{T}$ combinations $j=1,2, \ldots . p, p=4\left(p=2^{m}, m=2\right)$. During residual stresses and displacement analysis the problem of structure at shakedown solution vectors $F_{\text {sup }}$ and $F_{\text {inf }}$ must be prescribed, because of that quadrangle shown in Fig 2 is a constant form. This feature is applied because of duality theory direct application to structural analysis at shakedown. However, it is possible to take into account possible loading history, when only load variation bounds are given. It was achieved in this paper in two different ways. First, sequentially load variation field was extended in line with arbitrary increment (there are quadrangles marked by dotted lines in Fig 2). That is not an exact loading history evaluation. In residual stresses and displacements analysis problems particular loading history $\mathbf{F}(t)$ is evaluated more exactly if vector F components - forces assume increments $\Delta F$, but not their variation field. One of many possible histories $F(t)$ is shown as a continued line in Fig 2. Such loading history evaluation possibilities when solving actual residual forces $S_{r}$ and displacements $\mathbf{u}_{r}$ calculation questions are considered in mathematical model formation for incremental stress-strain analysis problems at shakedown (Fig 1). Only in this way it is possible to take into account

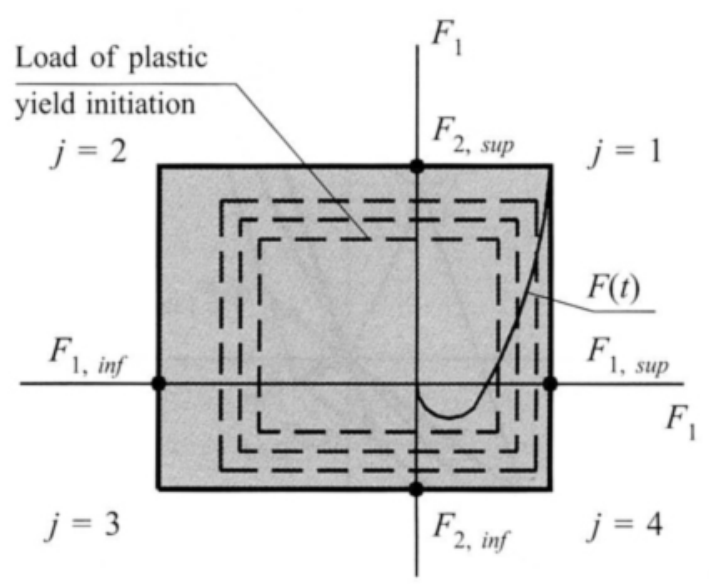

Fig 2. Two independent force variation field 
the unloading phenomenon in cross-sections of structure, which is practically necessarily appearing during adaptation.

Actually, in engineering practice an influence matrix

$$
[\alpha]=[K][A]^{T}\left([A][K][A]^{T}\right)^{-1},[K]=[D]^{-1}
$$

to internal forces $\mathbf{S}_{e}=[\alpha] \mathbf{F}$ evaluation is rarely applied. But find that the internal forces influence matrix $[\alpha]$ expressively illustrates an interaction of the internal forces $\mathbf{S}_{e}$ and load $\mathbf{F}$ when formulating the mathematical model of structure analysis and load optimization problems. Let us say that the actual load process is described via the time $t$ independent of load variation bounds $\mathbf{F}_{\text {inf }}$ and $\mathbf{F}_{\text {sup }}\left(\mathbf{F}_{\text {inf }} \leq \mathbf{F}(t) \leq F_{\text {sup }}\right)$. Then the certain distribution $\mathbf{S}_{e j}$ is calculated for each external forces combination $j$ (ie for the vector of loads variation bounds components $\mathbf{F}_{\text {inf }}, \mathbf{F}_{\text {sup }}$ ), all combinations being coupled to the set $j=1,2, \ldots . p, j \in J$. The elastic solution vectors $\mathbf{S}_{e j}$ are linear functions of the load variation bounds $\mathbf{F}_{\text {inf }}, \mathbf{F}_{\text {sup }}$ and define all vertices $j \in J$ of elastic force locus

$$
\mathbf{S}_{e}(t)=[\alpha] \mathbf{F}(t)
$$

Note that apexes of elastic locus are not located symmetrically regarding the coordinate system origin $O$ (Fig 3). Considering cyclic-plastic failure of the structure it is useful to make out symmetric $S_{e}$ apexes. It allows two identification types of failure: progressive plastic failure or an alternating plasticity [9].

Plasticity constant $C=\left(S_{0}\right)^{2}$ of elastic-plastic structure relates to dimensions and material of ideal form (sandwich) cross-section, ie, to limit force $S_{0}$ (Fig 4). Limit force $S_{0 k}(k \in K)$ is assumed as constant in the whole finite element. Non-linear yield condition

$$
\varphi=C-f\left(\mathbf{S}_{e}(t)+\mathbf{S}_{r}(t)\right) \geq 0
$$

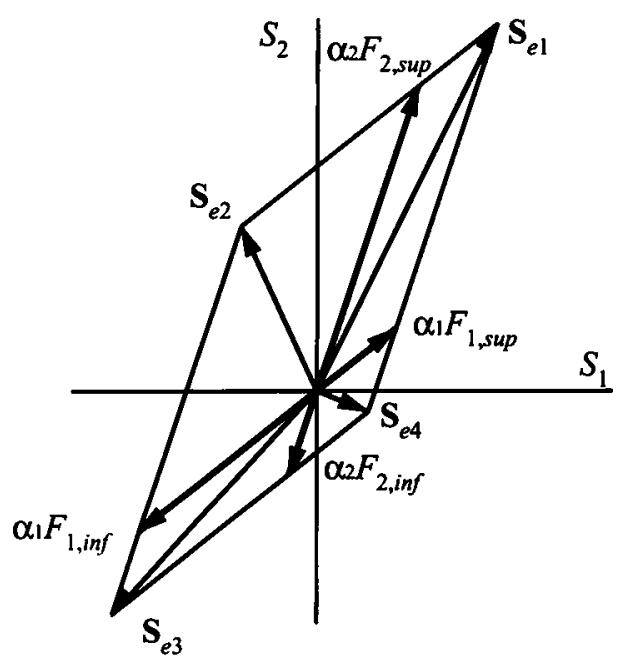

Fig 3. Elastic force locus

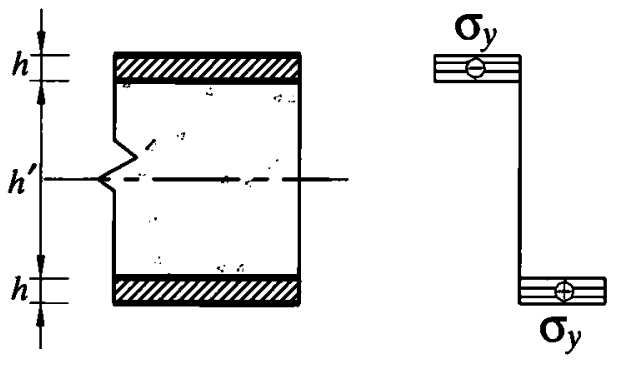

Fig 4. Three-layered bending plate cross-section

is written for that case, when adaptation process is considered in the time $t$ (taking into account all possible loading histories $\mathbf{F}(t)$ ). Residual forces $\mathbf{S}_{r}$ of the structure at shakedown must satisfy yield conditions (6) in each cross-section taking into account all apexes $j$ of elastic force locus $S_{e}(t)=[\alpha] \mathbf{F}(t)$ :

$$
\varphi_{j}=C_{k}-f_{j}\left(\mathbf{S}_{e j}+\mathbf{S}_{\mathrm{r}}\right) \geq 0, \quad j \in J .
$$

These yield conditions are verified in every $k$ finite element nodal point $l$ :

$$
\begin{gathered}
\varphi_{k l, j}=C_{k}-f_{k l, j}\left(\mathbf{S}_{e k l, j}+\mathbf{S}_{r k l}\right) \geq 0, \\
k \in K, l \in L, j \in J .
\end{gathered}
$$

For the entire elastic-plastic structure, using vectors $\mathbf{S}_{e j}$, $j \in J$, the conditions (8) can be rewritten as follows:

$$
\varphi_{j}=\mathbf{C}-\mathbf{f}_{j}\left(\mathbf{S}_{e j}+\mathbf{S}_{r}\right) \leq \mathbf{C}, j \in J .
$$

Here $\mathbf{C}=\left(C_{1}, C_{2}, \ldots, C_{k}, \ldots, C_{\eta}\right)^{T}$ is a vector of the whole structure plasticity constants. Hubert-Mises yield condition will be applied during consideration of elasticplastic plates. Statically admissible residual stresses $S_{r}$ satisfy equilibrium equations (2) and yield conditions (9).

\section{Direct applications of duality theory for structure analysis at shakedown}

\subsection{Static analysis problem formulation}

Residual force vector $S_{r}$ for structure at shakedown is obtained by solving static analysis problem formulation. This formulation is made on the basis of the minimum complementary deformation energy principle [7-9]:

of all statically admissible residual forces of structure at shakedown is the minimum complementary energy corresponding one.

The above-mentioned principle leads to the extremum problem as follows:

$$
\text { minimise } \frac{1}{2} \sum_{k} \mathbf{S}_{r k}^{T}\left[D_{k}\right] \mathbf{S}_{r k}=a^{*},
$$


subject to

$$
\begin{gathered}
\sum_{k}\left[A_{k}\right] \mathbf{s}_{r k}=0, \\
\mathbf{S}_{r k}=\left(\mathbf{S}_{r k 1}, \mathbf{S}_{r k 2}, \ldots, \mathbf{S}_{r k l}, \ldots, \mathbf{S}_{r k \eta_{k}}\right)^{T}, \\
\varphi_{k l, j}=C_{k}-f_{k l, j}\left(\mathbf{S}_{e k l, j}+\mathbf{S}_{r k l}\right) \geq 0, \\
C_{k}=\left(S_{0 k}\right)^{2}, k \in K, l \in L, j \in J,
\end{gathered}
$$

where structure limit force vector $\mathbf{S}_{0}=\left(s_{01}, S_{02}, \ldots, S_{0 k}, \ldots, S_{0 \eta}\right)^{T}$ is known. In yield conditions $\varphi_{k l, j}=C_{k}-f_{k l, j}\left(\mathbf{S}_{e k l, j}+\mathbf{S}_{r k l}\right) \geq 0$ all apexes $p, j \in J$ of elastic force locus (5) $\mathbf{S}_{e}(t)=[\alpha] \mathbf{F}(t)$ are taken into account. The functions $\varphi_{k l, j} \geq 0$ are convex, the matrix $\left[D_{k}\right]$ is positively defined, therefore optimal solution of analysis problem (10)-(14) is global and noted by $\mathbf{S}_{r}^{*}$. The adaptation of the structure is caused not by a minimum value of complementary deformation energy, but by the fact that there do not exist statically admissible, ie satisfying equilibrium equations (11), yield conditions (13)-(14) and residual forces $S_{r}[21,22]$.

\subsection{Kinematic analysis problem formulation}

Residual displacements $\mathbf{u}_{r}$ of the structure at shakedown are obtained by solving dual problem to the initial one (10)-(14):

maximise

$$
\begin{gathered}
\left\{-\frac{1}{2} \sum_{k} \mathbf{S}_{r k}^{T}\left[D_{k}\right] \mathbf{s}_{r k}-\sum_{k} \sum_{j} \lambda_{k, j}^{T}\left[\nabla \varphi_{k, j}\left(\mathbf{s}_{k, j}\right)\right] \mathbf{s}_{r k}-\right. \\
\left.-\sum_{k} \sum_{l} \sum_{j} \lambda_{k l, j}\left[c_{k}-f_{k l, j}\left(\mathbf{s}_{k l, j}\right)\right]\right\},
\end{gathered}
$$

subject to

$$
\begin{gathered}
{\left[D_{k}\right] \mathbf{S}_{r k}+\sum_{j}\left[\nabla \varphi_{k, j}\left(\mathbf{S}_{k, j}\right)\right]^{T} \lambda_{k, j}-\left[A_{k}\right]^{T} \mathbf{u}_{r}=0,} \\
\mathbf{S}_{k, j}=\left(\mathbf{S}_{e k, j}+\mathbf{S}_{r k}\right), \quad \lambda_{k, j} \geq 0, \\
k \in K, l \in L, j \in J .
\end{gathered}
$$

Components of plastic strain vector $\Theta_{p}=\left(\Theta_{p k l}\right)^{T}$, included in geometric equations, are determined by formula:

$$
\begin{gathered}
\Theta_{p k l}=\sum_{j} \Theta_{p k l, j}=\sum_{j}\left[\nabla \varphi_{k l, j}\left(\mathbf{S}_{e k l, j}+\mathbf{S}_{r k l}\right)\right]^{T} \lambda_{k l, j} \\
\lambda_{k l, j} \varphi_{k l, j}=0, \lambda_{k l, j} \geq 0 \\
k \in K, l \in L, j \in J
\end{gathered}
$$

$$
\text { Here }\left[\nabla \varphi_{k l, j}\left(\mathbf{S}_{e k l, j}+\mathbf{S}_{r k l}\right)\right]^{T}=\left[\frac{\partial f_{k l, j}\left(\mathbf{S}_{e k l, j}+\mathbf{S}_{r k l}\right)}{\partial \mathbf{S}_{r k l}}\right]
$$

are gradients of yield conditions (13)-(14), $\lambda_{k l, j}$ - plastic multipliers. In the problem (15)-(17) residual forces $\mathbf{S}_{r}$, displacements $\mathbf{u}_{r}$ and plasticity multipliers $\lambda_{j}$, $j \in J$ are assumed as unknowns. By changing the sign of the objective function (15) to the opposite, the following extremum energy principle is obtained:

of all kinematically admissible residual displacement distributions, the actual one corresponds the minimum of total potential energy.

The complementary slackness conditions

$$
\begin{gathered}
\lambda_{k l, j}\left(C_{k}-f_{k l, j}\left(\mathbf{s}_{k l, j}\right)\right)=0, \\
\lambda_{k l, j} \geq 0, \quad k \in K, l \in L, j \in J
\end{gathered}
$$

are incorporated in problems (15)-(17). According to the relations (19) at the moment of plastic strains deformation in the structure $j$-th cross-section the following relations are valid: $\varphi_{k l, j}=0, \quad \lambda_{k l, j} \varphi_{k l, j}=0$ and $\lambda_{k l, j}>0$. During structure deformation process, the magnitude of plasticity multiplier $\lambda_{k l, j}>0$ remains unchanged up to the loading end. The complementary slackness conditions do not allow direct evaluation of the unloading phenomenon (one can meet it when for an actual loading process $\left.\varphi_{k l}=c_{k}-f_{k l}\left(\mathbf{s}_{c, k l}^{v}+\Delta \mathbf{S}_{r k l}^{v}\right)>0\right)$. Optimal solution $\mathbf{S}_{r}^{*}, \mathbf{u}_{r}^{*}$ and $\lambda_{j}^{*}(j \in J)$ of the problem (15)-(17) is obtained without considering the loading history. Nevertheless, a particular loading history exists $\mathbf{F}(t)$ $\left(\mathbf{F}_{\text {inf }} \leq \mathbf{F}(t) \leq F_{\text {sup }}\right)$ which leads the structure to shakedown with $\mathbf{S}_{r}^{*}, \mathbf{u}_{r}^{*}$ and $\lambda_{j}^{*}$. It becomes obvious that the analysis problem mathematical model (10)-(14) of the structure at shakedown serves to structure with holonomic behaviour and can be obtained according to Haar-Kármán principle [16].

Residual displaceme $\mathbf{u}_{r}$ elimination from equations (16) leads to strain compatibility ones:

$$
-[B] \Theta_{p}=\left[B_{r}\right] \mathbf{S}_{r} .
$$

Here the matrices $[B],\left[B_{r}\right]$ read:

$$
\begin{gathered}
{[B]=\left[-\left[A^{\prime \prime}\right]^{T}\left(\left[A^{\prime}\right]^{T}\right)^{-1},[I]\right],} \\
{\left[B_{r}\right]=-\left[A^{*}\right]^{T}\left(\left[A^{\prime}\right]^{T}\right)^{-1}\left[D^{\prime}\right]+\left[D^{\prime \prime}\right] .}
\end{gathered}
$$

The Rozen project gradient method [17] is known as an algorithm for convex mathematical programming problem solution. The vector $\mathbf{S}_{r}^{*}$ is the optimal solution of the problem (10)-(14) if it satisfies the Rozen algorithm optimality criterion [23]. The Rozen optimality criterion coincides with the Kuhn-Tucker conditions known in 
mathematical programming. The Rozen criterion mathematical-mechanical interpretation: there are strain compatibility equations (20) (together with the complementary slackness conditions (19)) $[24,25]$. According to the Rozen criterion for problem (10)-(14) optimal solution plastic multipliers $\lambda$ *become known at once. Plastic strains $\Theta_{p}$ are determined from formulas (18). In this case it is not necessary to solve dual analysis problem (15)-(17) (Fig 5). That allows creating practical an iterative solution algorithm for incremental shakedown analysis problem.

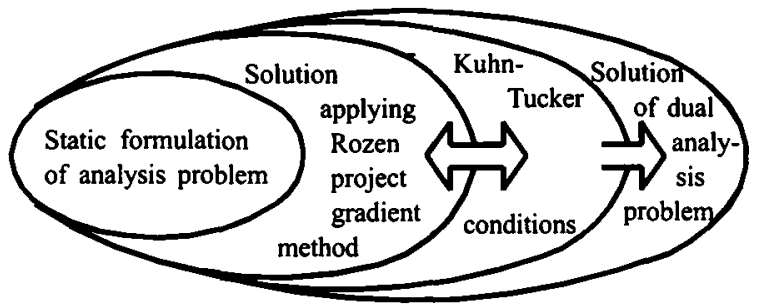

Fig 5. Connections between the Rozen criterion and KuhnTucker conditions

\section{Mathematical models of incremental structure analysis at shakedown}

\subsection{One active force evaluation}

Primarily the process of elastic-plastic structure deformation is under consideration, when one load $F(t)$ is acting. For each stage $v(v=1,2, \ldots, z, v \in V)$ of calculation process load increment $\Delta F^{v}$ is chosen freely. Sequentially increasing load by this load increment up to its final magnitude $F=\sum_{v} \Delta F^{v}$, each $v$-th stage increments of the residual stress and displacements $\Delta \mathbf{S}^{v}, \Delta \mathbf{u}^{v}$ are determined respectively. At the end of the plastic deformation $v$-th stage stress state of structure, discrete model is described by $n$-vector of total forces $\mathbf{S}^{\mathrm{v}}$ :

$$
\mathbf{S}^{v}=\mathbf{S}_{e}^{v}+\mathbf{S}_{r}^{v}
$$

here $\mathbf{S}_{e}^{\mathrm{v}}=\mathbf{S}_{e \Sigma}+\Delta \mathbf{S}_{e}^{\mathrm{v}}=\sum_{\mathrm{v}} \Delta \mathbf{S}_{e}^{\mathrm{v}-1}+\Delta \mathbf{S}_{e}^{\mathrm{v}}$ is a vector of pseudo-elastic stresses, and $\mathbf{S}_{r}^{\mathrm{V}}=\mathbf{S}_{r \Sigma}+\Delta \mathbf{S}_{r}^{\mathrm{V}}=$ $\sum \Delta \mathbf{S}_{r}^{v-1}+\Delta \mathbf{S}_{r}^{v}-$ vector of residual stresses at the end of the $v$-th stage. When $v=1$, usually the initial force vectors $\Delta \mathbf{S}_{r}^{v-1}=\Delta \mathbf{S}_{r}^{0}=0, \Delta \mathbf{S}_{e}^{v-1}=\Delta \mathbf{S}_{e}^{0}=\mathbf{0}$ (there are no other residual strains, only the $F$ caused ones, in the structure). Components of elastic stress increment vector $\Delta \mathbf{S}_{e}^{\nu}$ are calculated by the formula

$$
\Delta \mathbf{S}_{e}^{\vee}=\alpha \cdot \Delta F^{\vee}
$$

Here $\alpha$ - column of elastic calculation stress influence matrix $[\alpha]$ related to force $F$.

At the end of the $v$-th stage, total displacements $\mathbf{u}^{v}$ are obtained from the relation

$$
\mathbf{u}^{v}=\mathbf{u}_{e}^{v}+\mathbf{u}_{r}^{v} .
$$

Structure elastic displacements are as follows:

$$
\begin{gathered}
\mathbf{u}_{e}^{v}=\mathbf{u}_{e \Sigma}+\Delta \mathbf{u}_{e}^{v}=\sum_{v} \Delta \mathbf{u}_{e}^{v-1}+\Delta \mathbf{u}_{e}^{v}, \\
\Delta \mathbf{u}_{e}^{v}=\beta \cdot \Delta F^{v} .
\end{gathered}
$$

Here $\boldsymbol{\beta}$ - column of elastic calculation displacement influence matrix $[\beta]$. At the end of the $v$-th stage, residual displacements $\mathbf{u}_{r}^{\mathrm{v}}$ are calculated as follows:

$$
\mathbf{u}_{r}^{\nu}=\mathbf{u}_{r \Sigma}+\Delta \mathbf{u}_{r}^{v}=\sum_{v} \Delta \mathbf{u}_{r}^{v-1}+\Delta \mathbf{u}_{r}^{v} .
$$

The residual displacement increment $\Delta \mathbf{u}_{r}^{v}$ calculation at the end of $v$-th stage will be considered later.

Static formulation analysis problem (10)-(14) via residual force increments $\Delta S^{v}$ obtains the following form:

minimise

$$
\frac{1}{2} \sum_{k}\left(\mathbf{S}_{r \Sigma, k}+\Delta \mathbf{S}_{r k}^{v}\right)^{T}\left[D_{k}\right]\left(\mathbf{S}_{r \Sigma, k}+\Delta \mathbf{S}_{r k}^{\vee}\right)=a^{* v}
$$

subject to

$$
\sum_{k}\left[A_{k}\right] \Delta \mathbf{S}_{r k}^{\nu}=0
$$

$$
\begin{gathered}
\Delta \mathbf{S}_{r k}^{\vee}=\left(\Delta \mathbf{S}_{r k 1}^{\vee}, \Delta \mathbf{S}_{r k 2}^{\vee}, \ldots, \Delta \mathbf{S}_{r k l}^{\vee}, \ldots, \Delta \mathbf{S}_{r k \eta_{k}}^{\vee}\right)^{T}, \\
\varphi_{k l}=C_{k}-f_{k l}\left(\mathbf{S}_{c, k l}^{v}+\Delta \mathbf{S}_{r k l}^{\vee}\right) \geq 0, \\
\mathbf{S}_{c, k l}^{\vee}=\mathbf{S}_{e, k l}^{\vee}+\mathbf{S}_{r \Sigma, k l}=\mathbf{S}_{e \Sigma, k l}+\Delta \mathbf{S}_{e, k l}^{\vee}+\mathbf{S}_{r \Sigma, k l}, \\
\Delta \mathbf{S}_{e}^{v}=\alpha \cdot \Delta F^{\vee}, C_{k}=\left(S_{0 k}\right)^{2}, k \in K, l \in L .
\end{gathered}
$$

Problem (27)-(29) unknowns are residual force increment vector $\Delta \mathbf{S}_{r k}^{v}$ at the end of $v$-th stage (optimal problem solution is noted by $\Delta \mathbf{S}_{r k}^{* v}$ ). Residual forces $\mathbf{S}_{r \Sigma}$, like elastic ones $\mathbf{S}_{e}^{v}$ are known in the problem (27)-(29). At the end of the last stage of loading program elastic forces $\mathbf{S}_{e}$ are obtained from formula

$$
\mathbf{S}_{e}=\sum_{v=1}^{z} \Delta \mathbf{S}_{e}^{v-1}+\Delta \mathbf{S}_{e}^{z}
$$

and residual ones $\mathbf{S}_{r}-$ from relation 


$$
\mathbf{S}_{r}=\sum_{v=1}^{z} \Delta \mathbf{S}_{r}^{* v-1}+\Delta \mathbf{S}_{r}^{* z}
$$

When $\Delta \mathbf{S}_{e}^{0}=0, \Delta \mathbf{S}_{r}^{0}=0$, formulas (30), (31) obtain the form

$$
\mathbf{S}_{e}=\sum_{v=1}^{z} \Delta \mathbf{S}_{e}^{v}, \mathbf{S}_{r}^{*}=\sum_{v=1}^{z} \Delta \mathbf{S}_{r}^{* v} .
$$

Optimal solution $\Delta \mathbf{S}_{r}^{* v}$ is achieved when Rozen optimality criterion (Kuhn-Tucker conditions) [3] is satisfied (calculation schema, shown in Fig 5, serves and for incremental structural analysis at shakedown). Object function gradient $\nabla \propto$ and gradients of all constraints (equilibrium equations, yield conditions $\varphi \geq 0$ ) multiplied by Lagrange multipliers $\lambda^{v}$ and $\mathbf{u}_{r}^{v}$ are to be calculated in order to write the optimality criterion. Then KuhnTucker conditions are as follows:

$$
\begin{gathered}
{[D] \Delta \mathbf{S}_{r}^{* v}+[D] \mathbf{S}_{r \Sigma}+[\nabla \varphi]^{T} \lambda^{* v}-[A]^{T} \mathbf{u}_{r}^{* v}=\mathbf{0},} \\
\lambda^{* v T} \boldsymbol{\varphi}=\mathbf{0}, \lambda^{* v} \geq \mathbf{0}, v \in V .
\end{gathered}
$$

Here $[\nabla \varphi]^{T} \lambda^{* v}$ are total plastic strains at end of the $v$-th stage

$$
\Theta_{p}^{* \nu}=[\nabla \varphi]^{T} \lambda^{* \nu}, \lambda^{* v T} \varphi=0, \lambda^{* v} \geq 0 .
$$

Physical meaning of Lagrange multipliers: $\mathbf{u}_{r}^{* v}-$ total residual displacements (26) and total plastic multipliers $\lambda^{* v} \geq 0$ at the end of $v$-th stage.

At the end of the $v$-th stage vectors of plastic strain increments $\Delta \Theta_{p}^{* v}$ and residual displacement increments $\Delta \mathbf{u}_{r}^{* v}$ are calculated as follows:

$$
\begin{gathered}
\Delta \Theta_{p}^{* v}=\Theta_{p}^{* v}-\Theta_{p \Sigma}=\Theta_{p}^{* v}-\sum_{v} \Delta \Theta_{p}^{v-1}, \\
\Delta \mathbf{u}_{r}^{* v}=\mathbf{u}_{r}^{* v}-\mathbf{u}_{r \Sigma}=\mathbf{u}_{r}^{* v}-\sum_{v} \mathbf{u}_{r}^{v-1} .
\end{gathered}
$$

Plastic strains $\Theta_{p}^{z}$ at the end of loading program read:

$$
\Theta_{p}^{z}=\sum_{v=1}^{z} \Delta \Theta_{p}^{* v}
$$

This formula serves if only before was not any primary plastic strain $\Delta \Theta_{p}^{0}=0$.

When $\Delta \mathbf{u}_{r}^{0}=0$, residual displacements at the end of the loading process last stage can be calculated:

$$
\mathbf{u}_{r}^{z}=[H] \Theta_{p}^{z} .
$$

Here $[H]$ is the influence matrix of residual displacement:

$$
[H]=\left([A][D]^{-1}[A]^{T}\right)^{-1}[A][D]^{-1} .
$$

Problem (27)-(29) optimal solution of each stage $\Delta \mathbf{S}_{r}^{* v}$ can be tested by formula

$$
\Delta \mathbf{S}_{r}^{* v}=[G] \Delta \Theta_{p}^{* v},
$$

and solution (31) by relation

$$
\mathbf{S}_{r}=[G] \Theta_{p} .
$$

Here

$[G]=[D]^{-1}[A]^{T}\left([A][D]^{-1}[A]^{T}\right)^{-1}[A][D]^{-1}-[D]^{-1}$ is the residual force influence matrix.

\subsection{Several active force evaluation}

The technique proposed in the section 4.1 can be generalised for force increment vector $\Delta F$ (so can be realized the loading history $\mathbf{F}(t)$ shown as a continuous line in Fig 2). Then formula (24) obtains the form

$$
\Delta \mathbf{S}_{e}^{v}=[\alpha] \Delta \mathbf{F}^{v} .
$$

Further adapted structure analysis problem solution is performed according to in the section 4.1 explained analysis problem solution process without any changes. In this case, even though only load variation bounds $\mathbf{F}_{\text {inf }}, \mathbf{F}_{\text {sup }}$ are given, the particular loading history $\mathbf{F}(t)$ is taken into account (the same as in one force $F(t)$ case).

If sequentially load variation field is extended in line with an arbitrary increment, not changing its form (that are quadrangles marked by dotted lines in Fig 2), elastic locus apexes $j \in J$ in the mathematical model (27)-(29) yield conditions (29). Then the analysis problem (27)-(29) obtains the form:

minimise

$$
\frac{1}{2} \sum_{k}\left(\mathbf{S}_{r \Sigma, k}+\Delta \mathbf{S}_{r k}^{v}\right)^{T}\left[D_{k}\right]\left(\mathbf{S}_{r \Sigma, k}+\Delta \mathbf{S}_{r k}^{v}\right),
$$

subject to

$$
\begin{gathered}
\sum_{k}\left[A_{k}\right] \Delta \mathbf{S}_{r k}^{v}=\mathbf{0} \\
\Delta \mathbf{S}_{r k}^{v}=\left(\Delta \mathbf{S}_{r k 1}^{v}, \Delta \mathbf{S}_{r k 2}^{v}, \ldots, \Delta \mathbf{S}_{r k l}^{v}, \ldots, \Delta \mathbf{S}_{r k \eta_{k}}^{v}\right)^{T} \\
\varphi_{k l, j}=C_{k}-f_{k l, j}\left(\mathbf{S}_{c, k l, j}^{v}+\Delta \mathbf{S}_{r k l}^{v}\right) \geq 0 \\
\mathbf{S}_{c, k l, j}^{v}=\mathbf{S}_{e, k l, j}^{v}+\mathbf{S}_{r \Sigma, k l}= \\
=\sum_{v} \Delta \mathbf{S}_{e, k l, j}^{v-1}+\Delta \mathbf{S}_{e, k l, j}^{v}+\sum_{v} \Delta \mathbf{S}_{r, k i}^{v-1} \\
C_{k}=\left(S_{0 k}\right)^{2}, k \in K, l \in L, j \in J
\end{gathered}
$$


Problem (41)-(43) optimal solution is vector of residual force increments $\Delta S_{r k}^{* v}$ at the end of $v$-th stage. At the end of loading process, when $v=z$, residual forces $\mathbf{S}_{r}^{*}$ are obtained from the formula (32): $\mathbf{S}_{r}^{*}=\sum_{v=1}^{z} \Delta \mathbf{S}_{r}^{* v}$. The Kuhn-Tucker conditions (33)-(34) remain analogic to conditions (33)-(34):

$$
\begin{gathered}
{[D] \Delta \mathbf{S}_{r}^{* v}+[D] \mathbf{S}_{r \Sigma}+[\nabla \varphi]^{T} \lambda^{* v}-[A]^{T} \mathbf{u}_{r}^{* v}=\mathbf{0},} \\
\lambda^{* v T} \varphi=\mathbf{0}, \quad \lambda^{* v} \geq \mathbf{0}, \quad v \in V .
\end{gathered}
$$

Only plastic strains at the end of the $v$-th stage are calculated taking into account all apexes $j \in J$ of elastic force locus:

$$
\begin{gathered}
\Theta_{p k l}^{* v}=\sum_{j}\left[\nabla \varphi_{k l, j}\left(\mathbf{S}_{c, k l, j}^{v}+\Delta \mathbf{S}_{r k l}^{* v}\right)\right]^{T} \lambda_{k l, j}^{* v}, \\
k \in K, l \in L, j \in J .
\end{gathered}
$$

Residual displacements $\mathbf{u}_{r}$ are determined from formulas (36), (38), residual forces $\mathbf{S}_{r}$ can be checked applying the formula (39): $\mathbf{S}_{r}^{*}=[G] \Theta_{p}^{*}$.

Analysis of problem (41)-(43) optimal solution is actual residual forces $\mathbf{S}_{r}^{*}$; the result of iterative solution is actual residual displacements $\mathbf{u}_{r}^{*}$ and plastic strains $\Theta_{p}^{*}$ as well. Mathematical model (27)-(29) is a particular case of the problem (41)-(43), when $j=1$.

\subsection{Transformed mathematical model}

The mathematical model (41)-(43) can be transformed applying the residual force influence matrix

$$
[G]=[D]^{-1}[A]^{T}\left([A][D]^{-1}[A]^{T}\right)^{-1}[A][D]^{-1}-[D]^{-1}
$$

and plastic strains $\Theta_{p \Sigma}$ at the beginning of the $v$-th stage. Then residual forces $\mathbf{S}_{r \Sigma}=\sum_{\mathrm{v}} \Delta \mathbf{S}_{r}^{\mathrm{v}-1}$ are calculated according to the formula

$$
\mathbf{S}_{r \Sigma}=[G] \Theta_{p}^{v-1}
$$

Object function expression (41) is rewritten as follows:

$$
\begin{gathered}
\frac{1}{2} \Theta_{p \Sigma}^{T}[G]^{T}[D][G] \Theta_{p \Sigma}+ \\
+{ }_{2}^{1}\left(\Delta \mathbf{S}_{r}^{v}\right)^{T}[D] \Delta \mathbf{S}_{r}^{v}+\left(\Delta \mathbf{S}_{r}^{v}\right)^{T}[D][G] \Theta_{p \Sigma} .
\end{gathered}
$$

The first member of the expression (45) is constant

$$
{ }_{2}^{1} \Theta_{p \Sigma}^{T}[G]^{T}[D][G] \Theta_{p \Sigma}=\text { const }
$$

and does not influence the optimal solution $\Delta \mathbf{S}_{r}^{* v}$ of analysis problem (41)-(43) determination. Therefore this constant member (46) is not necessary to be incorporated into the object function. Mathematical model of incremental structural analysis at shakedown (41)-(43) obtains the form:

minimise $\left[\frac{1}{2} \Delta \mathbf{S}_{r}^{v T}[D] \Delta \mathbf{S}_{r}^{v}+\Delta \mathbf{S}_{r}^{v T}[D][G] \Theta_{p \Sigma}\right]$

subject to

$$
\begin{aligned}
& {[A] \Delta \mathbf{S}_{r}^{\nu}=\mathbf{0},} \\
& \Delta \mathbf{S}_{r}^{v}=\left(\Delta \mathbf{S}_{r 1}^{v}, \Delta \mathbf{S}_{r 2}^{v}, \ldots, \Delta \mathbf{S}_{r k}^{v}, \ldots, \Delta \mathbf{S}_{m}^{v}\right)^{T} \text {, } \\
& \Delta \mathbf{S}_{r k}^{v}=\left(\Delta \mathbf{S}_{r k 1}^{\mathrm{v}}, \Delta \mathbf{S}_{r k 2}^{\mathrm{v}}, \ldots, \Delta \mathbf{S}_{r k l}^{\mathrm{v}}, \ldots, \Delta \mathbf{S}_{r k \eta_{k}}^{\mathrm{v}}\right)^{T} \text {, } \\
& \boldsymbol{\varphi}_{k l, j}=C_{k}-f_{k l, j}\left(\mathbf{s}_{c, k l, j}^{\mathrm{v}}+\Delta \mathbf{S}_{r k l}^{\mathrm{v}}\right) \geq 0, \\
& \mathbf{S}_{c, k l, j}^{\vee}=\mathbf{S}_{e, k l, j}^{\vee}+\mathbf{S}_{r \Sigma, k l}= \\
& =\sum_{v} \Delta \mathbf{S}_{e, k l, j}^{v-1}+\Delta \mathbf{S}_{e, k l, j}^{\mathrm{v}}+\sum_{v} \Delta \mathbf{S}_{r, k l}^{v-1}, \\
& C_{k}=\left(S_{0 k}\right)^{2}, k \in K, l \in L, j \in J .
\end{aligned}
$$

Optimal solution $\Delta \mathbf{S}_{r}^{* v}$ is achieved when the Rozen optimality criterion (Kuhn-Tucker conditions) [3] is satisfied:

$$
[D] \Delta \mathbf{S}_{r}^{* v}+[D][G] \Theta_{p \Sigma}+[\nabla \varphi]^{T} \lambda^{* v}-[A]^{T} \mathbf{u}_{r}^{* v}=\mathbf{0},
$$

$$
\lambda^{* v T} \varphi=0, \quad \lambda^{* v} \geq 0 .
$$

Physical meaning of the second and third members of relations (50) is explained in more detail. Member $[D][G] \Theta_{p \Sigma}$ means elastic strains from accumulated plastic strains $\Theta_{p \Sigma}=\sum_{v} \Delta \Theta_{p}^{v-1}$ at the beginning of $v$-th stage because

$$
\mathbf{S}_{r}^{v-1}=[G] \Theta_{p \Sigma}
$$

But then

$$
\begin{gathered}
{[D][G] \Theta_{p \Sigma}=[D]\left\{[D]^{-1}[A]^{T}\left([A][D]^{-1}[A]^{T}\right)^{-1} \times\right.} \\
\left.\times[A][D]^{-1}-[D]^{-1}\right\} \Theta_{p \Sigma}= \\
=\left\{[A]^{T}\left([A][D]^{-1}[A]^{T}\right)^{-1}[A][D]^{-1}-[I]\right\} \Theta_{p \Sigma}= \\
=[A]^{T} \mathbf{u}_{r \Sigma}-\Theta_{p \Sigma} .
\end{gathered}
$$

Influence matrix of residual displacements $[H]=\left([A][D]^{-1}[A]^{T}\right)^{-1}[A][D]^{-1}$ is applied to 
influence the expression (53). Then applying relation (53), geometric equations $(50)$ can be written as follows:

$$
[D] \Delta \mathbf{S}_{r}^{* v}+[A]^{T} \mathbf{u}_{r \Sigma}-\Theta_{p \Sigma}+\Theta_{p}^{* v}-[A]^{T} \mathbf{u}_{r}^{* v}=\mathbf{0}
$$

Having introduced vectors of residual displacement and plastic strain increments in the $v$-th stage

$$
\begin{aligned}
\Delta \mathbf{u}_{r}^{* v} & =\mathbf{u}_{r}^{* v}-\mathbf{u}_{r \Sigma}, \\
\Delta \Theta_{p}^{* v} & =\Theta_{p}^{* \mathrm{v}}-\Theta_{p \Sigma}
\end{aligned}
$$

geometric equations (54) are rewritten by means of residual force, displacement and plastic strains increments as follows:

$$
[D] \Delta \mathbf{S}_{r}^{* v}+\Delta \Theta_{p}^{* v}=[A]^{T} \Delta \mathbf{u}_{r}^{* v} .
$$

Full equation system for the structure undergone a plastic deformation is next to consideration. It consists of analysis problem constraints and Kuhn-Tucker conditions $(50)-(51)$ :

$$
\begin{gathered}
{[A] \Delta \mathbf{S}_{r}^{v}=\mathbf{0}} \\
\varphi=\mathbf{C}-\mathbf{f}\left(\mathbf{S}_{e}^{v}+\Delta \mathbf{S}_{r}^{v}\right) \geq \mathbf{0} \\
\left(\varphi=\left(\varphi_{k l, j}\right)^{T} \text { for all } k \in K, l \in L, j \in J\right) \\
{[D] \Delta \mathbf{S}_{r}^{v}+[D][G] \Theta_{p \Sigma}+[\nabla \varphi]^{T} \lambda^{v}-[A]^{T} \mathbf{u}_{r}^{v}=\mathbf{0},} \\
\lambda^{v T} \varphi=\mathbf{0}, \quad \lambda^{v} \geq \mathbf{0} .
\end{gathered}
$$

Having solved (58), formulas for residual force increment $\Delta \mathbf{S}_{r}^{\mathrm{v}}$ at the $v$-th stage and total residual displacements $\mathbf{u}_{r}^{\mathrm{v}}$ at the end of stage calculation are obtained:

$$
\begin{gathered}
\Delta \mathbf{S}_{r}^{v}=[G]\left([D][G] \Theta_{p \Sigma}+[\nabla \varphi]^{T} \lambda^{v}\right)= \\
=\left\{[D]^{-1}[A]^{T}\left([A][D]^{-1}[A]^{T}\right)^{-1}[A][D]^{-1}-[D]^{-1}\right\} \\
\left(\left[[D][G] \Theta_{p \Sigma}+[\nabla \varphi]^{T} \lambda^{v}\right)=\right. \\
=\left\{[D]^{-1}[A]^{T}\left([A][D]^{-1}[A]^{P}\right)^{-1}[A]-[I]\right\}[G] \Theta_{p \Sigma}^{+} \\
\left.+[G][\nabla \varphi]^{r} \lambda^{v}\right)=-[G] \Theta_{p \Sigma}+[G] \Theta_{p}^{v}=[G] \Delta \Theta_{p}^{v}, \\
\mathbf{u}_{r}^{v}=[H]\left([D][G] \Theta_{p \Sigma}+[\nabla \varphi]^{T} \lambda^{v}\right)= \\
=\left([A][D]^{-1}[A]^{T}\right)^{-1}[A][D]^{-1}\left([D][G] \Theta_{p \Sigma}+[\nabla \varphi]^{T} \lambda^{v}\right)= \\
=[H][\nabla \varphi]^{T} \lambda^{v}=[H] \Theta_{p}^{v} .
\end{gathered}
$$

\subsection{About cross-section unloading phenomenon}

According to the associative flow rule [6] ,

$$
\lambda \geq 0, \text { if } \varphi(\mathbf{s})=0
$$

and there is not any unloading phenomenon. Strictly speaking, unloading phenomenon is determined by the following condition:

$$
\dot{\varphi}(\mathbf{S})=\frac{\partial \varphi(\mathbf{s})}{\partial \mathbf{S}} \dot{\mathbf{S}}<0
$$

Here $\dot{\mathbf{S}}$ is force velocity.

In the section 3.2 unloading phenomenon is determined as a case for an actual loading process, when

$$
\begin{gathered}
\lambda_{i}>0, \\
\varphi_{i}=C_{i}-f_{i}\left(\mathbf{s}_{i}\right) \geq 0, \\
i=1,2, \ldots, \zeta, \quad i \in I .
\end{gathered}
$$

Applying incremental method for structural analysis at shakedown it is possible to fix satisfaction of the condition (62)-(63). Mathematical models (27)-(29), (41) $-(43)$ and (47) $-(49)$ of analysis problem can serve for that. All these models of shakedown analysis are related to Haar-Kármán principle. This principle requires that during all loading stages the unloading phenomenon (when conditions (62)-(63) are satisfied) does not appear in any structure cross-section. When Mises yield conditions are applied, Haar-Kármán principle will be right if one more requirement is satisfied. That is the stress state, satisfying condition

$$
\varphi(\mathbf{S})=0,
$$

and it has to remain unchanged during the plastic deformation.

The above-mentioned requirements are taken into account verifying the sign of plastic multiplier increments at each calculation stage:

$$
\Delta \lambda_{i}^{\nu}=\lambda_{i}^{\nu}-\lambda_{i}^{\nu-1}, \quad i=1,2, \ldots, \zeta, i \in I .
$$

When it is noticed that

$$
\Delta \lambda_{i}^{v}<0
$$

it means that the unloading phenomenon is developing in the $i$-th cross-section. Even though this moment is fixed formally, the analysis problem solution is continued in order to be sure that the unloading phenomenon really appeared in the cross-section, ie that conditions (62)-(63) are satisfied.

In the paper proposed mathematical models of incremental analysis allow the determination of unloading phenomenon only at one (the first) cross-section. Having fixed that, for further shakedown analysis the expression of yield condition must be modified (fictitious plasticity constant is introduced) in the mathematical models (27) $-(29),(41)-(43)$ and (47) $-(49)$. New problems are 
not detailed here, just creation of technique allowing to identify the moment of unloading phenomenon appearance at the cross-section.

\section{Incremental shakedown analysis of plate}

\subsection{Plate analysis mathematical model}

Mathematical model of the bending plate static formulation analysis is obtained from the problem (41)-(43):

minimise $\frac{1}{2} \Delta \mathbf{M}_{r}^{v T}[D] \Delta \mathbf{M}_{r}^{v}+\Delta \mathbf{M}_{r}^{v T}[D][G] \Theta_{p \Sigma}$,

subject to

$$
[A] \Delta \mathbf{M}_{r}^{\vee}=\mathbf{0}
$$

$$
\begin{gathered}
\Delta \mathbf{M}_{r k}^{v}=\left(\Delta \mathbf{M}_{r k l}^{v}, \Delta \mathbf{M}_{r k 2}^{v}, \ldots, \Delta \mathbf{M}_{r k l}^{v}, \ldots, \Delta \mathbf{M}_{r k \eta_{k}}^{v}\right)^{T}, \\
\varphi_{k l, j}=C_{k}-\mathbf{M}_{k l, j}^{v T}[\Phi] \mathbf{M}_{k l, j}^{v} \geq 0, \quad C_{k}=\left(M_{0 k}\right)^{2} \\
\mathbf{M}_{k l, j}^{v}=\mathbf{M}_{c, k l, j}^{v}+\Delta \mathbf{M}_{r, k l}^{v}, \\
\mathbf{M}_{c, k l, j}^{v}=\mathbf{M}_{e, k l, j}^{v}+\mathbf{M}_{r \Sigma, k l}= \\
=\sum_{v} \Delta \mathbf{M}_{e, k l, j}^{v-1}+\Delta \mathbf{M}_{e, k l, j}^{v}+\sum_{v} \Delta \mathbf{M}_{r, k i}^{v-1}, \\
k \in K, l \in L, j \in J .
\end{gathered}
$$

A particular case of mathematical model (67)-(69) is obtained for certain loading history $\mathrm{F}(t)$ consideration: minimise $\frac{1}{2} \Delta \mathbf{M}_{r}^{v T}[D] \Delta \mathbf{M}_{r}^{v}+\Delta \mathbf{M}_{r}^{v T}[D][G] \Theta_{p \Sigma}$,

subject to

$$
[A] \Delta \mathbf{M}_{r}^{\nu}=\mathbf{0}
$$

$$
\begin{gathered}
\Delta \mathbf{M}_{r k}^{v}=\left(\Delta \mathbf{M}_{r k 1}^{v}, \Delta \mathbf{M}_{r k 2}^{v}, \ldots, \Delta \mathbf{M}_{r k l}^{v}, \ldots, \Delta \mathbf{M}_{r k \eta_{k}}^{v}\right)^{T}, \\
\varphi_{k l}=C_{k}-\mathbf{M}_{k l}^{v T}[\Phi] \mathbf{M}_{k l}^{v} \geq 0, C_{k}=\left(M_{0 k}\right)^{2}, \\
\mathbf{M}_{k l}^{v}=\mathbf{M}_{c, k l}^{v}+\Delta \mathbf{M}_{r, k l}^{v}, \mathbf{M}_{c, k l}^{v}=\mathbf{M}_{e, k l}^{v}+\mathbf{M}_{r \Sigma, k l}, \\
k \in K, l \in L .
\end{gathered}
$$

Here $[\Phi]$ is von Mises yield condition matrix. Problems (67)-(69), (70)-(72) unknowns are residual moment increments $\Delta \mathbf{M}_{r}^{v}$. After optimal solution $\Delta \mathbf{M}_{r}^{* v}$ determination of each $v$-th loading stage, the plastic deformations $\Theta_{p}^{* v}$ and residual displacements $\mathbf{u}_{r}^{* v}$ are found.

\subsection{Initial admissible solution for analysis problem}

Solving the analysis problem (10)-(14) or (67)-(69), (70)-(72) by the Rozen project gradient method, the determination of initial admissible point $\mathbf{x}$ is important. Global solution of load optimization or optimal design problems obtained when structure has reached limit state resulted by cyclic-plastic failure, can serve for that. Load optimization mathematical model for bending plate reads:

$$
\text { maximise }\left\{\mathbf{T}_{\text {sup }}^{T} \mathbf{F}_{\text {sup }}+\mathbf{T}_{\text {inf }}^{T} \mathbf{F}_{\text {inf }}\right\},
$$

subject to

$$
[A] \mathbf{M}_{r}=\mathbf{0}
$$

$$
\begin{gathered}
\varphi_{k l, j}=C_{k}-\left(\mathbf{M}_{e k l, j}+\mathbf{M}_{r k l}\right)^{T}[\Phi]\left(\mathbf{M}_{e k l, j}+\mathbf{M}_{r k l}\right) \geq 0, \\
C_{k}=\left(M_{0 k}\right)^{2}, \quad k \in K, \quad l \in L, \quad j \in J .
\end{gathered}
$$

As a numerical example will be shown for circular plate, in this case von Mises yield condition reads:

$$
M_{\rho}^{2}-M_{\rho} M_{\Theta}+M_{\Theta}^{2} \leq\left(M_{0}\right)^{2} .
$$

Here

$$
[\Phi]=\left[\begin{array}{cc}
1 & -0,5 \\
-0,5 & 1
\end{array}\right]
$$

Optimal solution of problem (73)-(75) means load variation bounds $\mathbf{F}_{\text {inf }}^{*}, \mathbf{F}_{\text {sup }}^{*}$ and residual moments $\mathbf{M}_{r}^{*}$. Vector $\mathbf{M}_{r}^{*}$ is initial admissible point $\mathbf{x}$ of analysis problem solved applying the Rozen algorithm.

Having changed object function (73) of the problem (73)-(75) to minimise $\frac{1}{2} \mathbf{M}_{r}^{T}[D] \mathbf{M}_{r}=a^{*}$, analysis problem (10)-(14) mathematical model for plates can be obtained. In this case the loading history is neglected.

\subsection{Numeric examples of the plate analysis problem}

Perfectly elastic-plastic annular plate with external radii $R$ (Fig 6) is under consideration. The hinge-supported on external contour plate is subjected to uniformly distributed load $q\left(0 \leq q \leq q_{\text {sup }}\right)$ and to the internal contour uniformly distributed moment $M$ ( $0 \leq M \leq M_{\text {sup }}$ ). The limit bending moment of the plate $M_{0}$, stiffness $\mathscr{K}$ are prescribed. Equilibrium finite element method is applied for plate discretisation [26].

The considered example is simple and serves only for illustration of proposed solution technique. Therefore the segment of annular plate is subdivided into three finite elements $(k=1,2,3)$. An element $k(k \in K)$ contains three nodal points $l=1,2,3(l \in L)$. Hence the vector of bending moments due to the applied cylindric co-ordinate system is: $\mathbf{M}_{k}=\left(M_{\rho, k 1}, M_{\theta, k 1}, M_{\rho, k 2}\right.$, $\left.M_{\theta, k 2}, M_{\rho, k 3}, M_{\theta, k 3}\right)^{T}=\left(\mathbf{M}_{k 1}, \mathbf{M}_{k 2}, \mathbf{M}_{k 3}\right)^{T}$. 


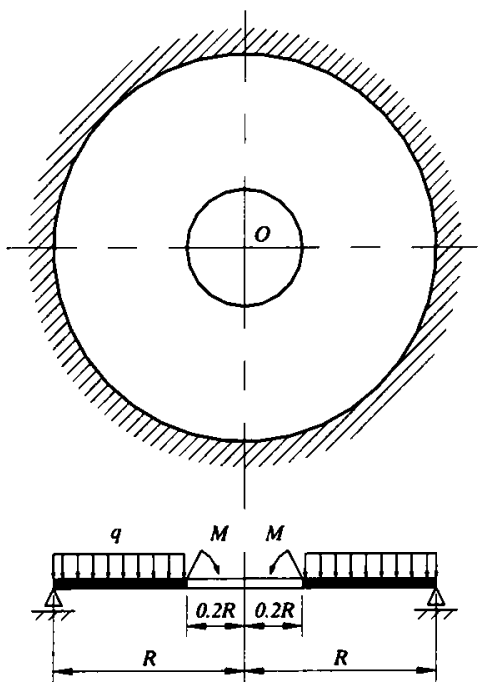

Fig 6. Annular plate

Here $\mathbf{M}_{k l}=\left(M_{\rho, k l}, M_{\theta, k l}\right)^{T}$. Moment vector of plate discrete model is $\mathbf{M}=\left(\mathbf{M}_{1}, \mathbf{M}_{2}, \ldots, \mathbf{M}_{k}, \ldots, \mathbf{M}_{\eta}\right)^{T}$. There are 9 nodes where von Mises yield conditions are verified.

Non-linear problems are solved applying the software (Rozen algorithm, FORTRAN) created by the authors of this paper.

Example 1. Annular plate (Fig 6) is considered. Maximal variation bound $q_{\text {sup }}\left(0 \leq q \leq q_{\text {sup }}\right)$ is to be found ( $M=0$ ) according to cyclic-plastic failure conditions.

The problem is solved applying mathematical model (73)-(75):

$$
\text { maximise } q=q_{\text {sup }},
$$

subject to (74), (75).

Plate elastic moments $\mathbf{M}_{e}=\left(\mathbf{M}_{e 1}, \mathbf{M}_{e 2}, \mathbf{M}_{e 3}\right)^{T}$ are linear $q$ functions (Table 1) (one locus apex). Elastic moments, given in Table 1 , are determined by exact formulas [27] and result in the influence matrix $[\alpha]$. The optimal solution of the problem (77)-(75) are $q_{\text {sup }}^{*}=4,8950 M_{0} R^{-2}$ and residual moments $\mathbf{M}_{r}^{*}$ (Table 2). Von Mises yield conditions (75) are satisfied as equalities in cross-sections $1,3,5,6,8,9$.

Table 1. Plate moments $\mathbf{M}_{e}(q)$ Table 2. Plate moments $\mathbf{M}_{r}^{*}$

\begin{tabular}{|c|c|}
\hline$M_{\rho e}$ & $M_{\Theta e}$ \\
\hline 0 & 0,36541 \\
\hline 0,11003 & 0,24556 \\
\hline 0,12492 & 0,20477 \\
\hline 0,12492 & 0,20477 \\
\hline 0,11224 & 0,17773 \\
\hline 0,08496 & 0,15245 \\
\hline 0,08496 & 0,15245 \\
\hline 0,04703 & 0,12540 \\
\hline 0 & 0,095257 \\
\hline
\end{tabular}

\begin{tabular}{|c|c|}
\hline$M_{\rho r}$ & $M_{\Theta r}$ \\
\hline 0 & $-0,78868$ \\
\hline$-0,36012$ & $-0,84626$ \\
\hline$-0,38891$ & 0,09016 \\
\hline$-0,38891$ & 0,07058 \\
\hline$-0,26685$ & 0,24089 \\
\hline$-0,16325$ & 0,35584 \\
\hline$-0,16325$ & 0,34323 \\
\hline$-0,07639$ & 0,45416 \\
\hline 0 & 0,53370 \\
\hline
\end{tabular}

Example 2. Annular plate subjected to the distributed load $q=4,355047 M_{0} R^{-2}$ undergoes plastic strains not reaching cyclic-plastic failure $(M=0)$. The analysis of problems (10)-(14) is performed.

Elastic moments $\mathbf{M}_{e}$ are obtained by multiplying moments presented in Table 1 by load $q=4,355047 M_{0} R^{-2}$ (Table 3). Problem (10)-(14) optimal solution is complementary deformation energy $a^{*}=1,8647 M_{0}^{2} R^{-2} / \circlearrowright \mathcal{K}$ and residual moments $\mathbf{M}_{r}^{*}$. Using mathematical-mechanical interpretation of the Rozen optimality criterion, plastic multipliers $\lambda_{k l}$, ie vector

$\lambda=\left(\lambda_{11}, \lambda_{12}, \lambda_{13}, \lambda_{21}, \lambda_{22}, \lambda_{23}, \lambda_{31}, \lambda_{32}, \lambda_{33}\right)^{T}$, vector of plastic strains $\Theta_{p}$ and residual displacements $\mathbf{u}_{r}$ are determined (Table 3 ).

Example 3. Annular load is subjected to uniformly distributed load $q\left(0 \leq q \leq 4,355047 M_{0} R^{-2}\right)$ and bending moment $M\left(0 \leq M \leq 0,176362 M_{0}\right)$ (Fig 6). Loading program: when $M=0$, the uniformly distributed load is increased by stages up to $q=4,355047 M_{0} R^{-2}$, later, holding uniformly distributed load magnitude $q=4,355047 M_{0} R^{-2}$ constant, moment $M$ is increased by stages from 0 up to $M=0,176362 M_{0}$. Plate stress-strain state is considered in each loading stage. These results are compared to the analysis problem solution obtained neglecting the loading history.

Analysis problem is solved by two different ways: according to incremental analysis problem mathematical model (70)-(72) and according mathematical model (10)-(14) written for plates where loading history is neglected. Perfectly elastic plate moments, needed for analysis problem solution according both models, are written in Table 4.

Presented in Table 5 residual moments $\mathbf{M}_{r}^{* v}$ are obtained for all seven calculation stages of plate incremental analysis problem (70)-(72). Though optimal solution of each analysis problem stage is $\Delta \mathbf{M}_{r}^{* v}$, total residual moments at the end of $v$-th stage $\mathbf{M}_{r}^{* \mathrm{v}}=\mathbf{M}_{r \Sigma}+\Delta \mathbf{M}_{r}^{* \mathrm{v}}$ are presented in Table 5. The analysis problem (70)-(72) is solved considering in detail all loading history, but neglecting possible unloading phenomenon. For comparison, intermediate results of analysis problem (10)-(14) are presented in the same Table 5 obtained without loading history evaluation. Analysis of results in Table 5 shows that mathematical model of incremental analysis is formed correctly: the results of the 5 th, 6 th, 7 th calculation stage coincide with residual moments $\mathbf{M}_{r}^{*}$ obtained via analysis problem (10)-(14) solution. If unloading phenomenon appeared during loading process, it is possible to determine analysing values of plastic multipliers $\lambda^{* v}$ presented in Table 6. From the 5th stage when at the first node of the 
Table 3. Optimal solution of annular plate analysis problem (10)-(14) (when $q=4,355047 M_{0} R^{-2}$ ).

\begin{tabular}{|c|c|c|c|c|c|c|}
\hline Elements & Nodes & $\mathbf{M}_{e}$ & $\mathbf{M}_{r}^{*}$ & $\mathbf{M}_{e}+\mathbf{M}_{r}^{*}$ & $\lambda$ & $\theta_{p}$ \\
\hline \multirow{5}{*}{1} & 1 & $\frac{0}{1,5914}$ & $\begin{array}{c}0 \\
-0,59142\end{array}$ & $\begin{array}{c}0 \\
0,9996\end{array}$ & 3,9100 & $\begin{array}{c}-3,9099 \\
7,8197\end{array}$ \\
\hline & \multirow{2}{*}{2} & 0,47919 & $-0,26157$ & 0,21761 & \multirow[b]{2}{*}{0} & 0 \\
\hline & & 1,0694 & $-0,58375$ & 0,48567 & & 0 \\
\hline & \multirow{2}{*}{3} & 0,54403 & $-0,25774$ & 0,28629 & \multirow{2}{*}{1,3546} & $-0,73059$ \\
\hline & & 0,89178 & 0,22013 & 1,1119 & & 2,6246 \\
\hline \multirow{6}{*}{2} & \multirow{2}{*}{1} & 0,54403 & $-0,25774$ & 0,28629 & \multirow{2}{*}{0,22850} & $-0,12323$ \\
\hline & & 0,89178 & 0,22011 & 1,1119 & & 0,44271 \\
\hline & \multirow{2}{*}{2} & 0,48881 & $-0,14188$ & 0,34693 & \multirow{2}{*}{0} & 0 \\
\hline & & 0,77402 & 0,28646 & 1,0605 & & 0 \\
\hline & \multirow{2}{*}{3} & 0,37000 & $-0,067366$ & 0,30264 & \multirow{2}{*}{0} & 0 \\
\hline & & 0,66393 & 0,22879 & 0,89271 & & 0 \\
\hline \multirow{6}{*}{3} & \multirow{2}{*}{1} & 0,37000 & $-0,067366$ & 0,30264 & \multirow{2}{*}{0} & 0 \\
\hline & & 0,66393 & 0,20029 & 0,86422 & & 0 \\
\hline & \multirow{2}{*}{2} & 0,20481 & $-0,026192$ & 0,17862 & \multirow{2}{*}{0} & 0 \\
\hline & & 0,54612 & 0,19275 & 0,73887 & & 0 \\
\hline & \multirow{2}{*}{3} & 0 & 0 & 0 & \multirow[b]{2}{*}{0} & 0 \\
\hline & & 0,41485 & 0,14026 & 0,55511 & & 0 \\
\hline
\end{tabular}

Table 4. Vectors $\mathbf{M}_{e 1}, \mathbf{M}_{e 2}, \mathbf{M}_{e 3}$

\begin{tabular}{|c|c|c|c|c|c|}
\hline \multicolumn{2}{|c|}{$M_{e 1}(q)$} & \multicolumn{2}{c|}{$M_{e 2}(M)$} & \multicolumn{2}{c|}{$M_{e 3}(q, M)$} \\
\hline$M_{\rho}$ & $M_{\Theta}$ & $M_{\rho}$ & $M_{\Theta}$ & $M_{\rho}$ & $M_{\Theta}$ \\
\hline 0 & 0,36541 & 1,0 & $-1,03710$ & $1,0 M$ & $0,36541 q-1,03710 M$ \\
\hline 0,11003 & 0,24556 & 0,33350 & $-0,40802$ & $0,11003 q+0,33350 M$ & $0,24556 q-0,40802 M$ \\
\hline 0,12492 & 0,20477 & 0,14967 & $-0,23108$ & $0,12492 q+0,14967 M$ & $0,20477 q-0,23108 M$ \\
\hline 0,12492 & 0,20477 & 0,14967 & $-0,23123$ & $0,12492 q+0,14967 M$ & $0,20477 q-0,23123 M$ \\
\hline 0,11224 & 0,17773 & 0,074078 & $-0,15664$ & $0,11224 q+0,074078 M$ & $0,17773 q-0,15664 M$ \\
\hline 0,08496 & 0,15245 & 0,035815 & $-0,11881$ & $0,08496 q+0,035815 M$ & $0,15245 q-0,11881 M$ \\
\hline 0,08496 & 0,15245 & 0,035815 & $-0,11885$ & $0,08496 q+0,035815 M$ & $0,15245 q-0,11885 M$ \\
\hline 0,047028 & 0,12540 & 0,013807 & $-0,09697$ & $0,047028 q+0,013807 M$ & $0,12540 q-0,09697 M$ \\
\hline 0 & 0,095257 & 0 & $-0,083241$ & $0,095257 M$ & $0,095257 q-0,083241 M$ \\
\hline
\end{tabular}

Table 5. Annular plate analysis problem (example 3): residual moments $\mathbf{M}_{r}^{*}$.

\begin{tabular}{|c|c|c|c|c|c|c|c|c|c|c|c|}
\hline \multirow{2}{*}{ 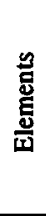 } & \multirow{2}{*}{$\frac{\pi}{8}$} & \multicolumn{7}{|c|}{$\begin{array}{l}\text { Incremental analysis problem (70)-(72): } \mathbf{M}_{r}^{* v} \text { at the end of each stage } \\
\qquad v=1,2, \ldots, 7 \quad\left(\mathbf{M}_{r}^{* v}=\mathbf{M}_{r}+\Delta \mathbf{M}_{r}^{* v}\right)\end{array}$} & \multicolumn{3}{|c|}{$\begin{array}{l}\text { Analysis problem }(10)-(14) \text { : } \\
\text { optimal solution } \mathbf{M}_{r}^{*}\end{array}$} \\
\hline & & $\begin{array}{c}1 \\
q=2,740 \\
M=0,0\end{array}$ & $\begin{array}{c}2 \\
q=3,276 \\
M=0,0\end{array}$ & $\begin{array}{c}3 \\
q=3,815 \\
M=0,0\end{array}$ & $\begin{array}{c}4 \\
q=4,355 \\
M=0,0\end{array}$ & $\begin{array}{c}5 \\
q=4,355 \\
M=0,1\end{array}$ & $\begin{array}{c}6 \\
q=4,355 \\
M=0,15\end{array}$ & $\begin{array}{c}7 \\
q=4,355 \\
M=0,176\end{array}$ & $\begin{array}{l}q=4,355 \\
M=0,1\end{array}$ & $\begin{array}{l}q=4,355 \\
M=0,15\end{array}$ & $\begin{array}{c}Q=, 355 \\
M=0,176\end{array}$ \\
\hline \multirow{6}{*}{1} & 1 & 0,00000 & 0,00000 & 0,00000 & 0,00000 & 0,00000 & 0,00000 & 0,00000 & 0,00000 & 0,00000 & 00000 \\
\hline & & $-0,00119$ & $-0,19698$ & $-0,39422$ & $-0,59142$ & 0,74880 & $-0,83038$ & $-0,87423$ & 883 & & \\
\hline & $?$ & $-0,00045$ & $-0,07423$ & $-0,16326$ & $-0,26158$ & $-0,33769$ & $-0,37733$ & $-0,39870$ & \begin{tabular}{|c|}
$-0,33770$ \\
\end{tabular} & $-0,37734$ & $-0,39878$ \\
\hline & 2 & $-0,00071$ & $-0,11710$ & $-0,32254$ & $-0,58376$ & $-0,77811$ & $-0,88000$ & $-0,93515$ & \begin{tabular}{|l|}
$-0,77814$ \\
\end{tabular} & $-0,88004$ & $-0,93535$ \\
\hline & & $-0,00021$ & $-0,03429$ & $-0,12742$ & $-0,25774$ & 5234 & $-0,40214$ & $-0,42916$ & -0 & $-0,40216$ & 2926 \\
\hline & 3 & 0,00184 & 0,30530 & 0,34644 & 0,22012 & 0,16166 & 0,12791 & 0,10863 & 0,16167 & 0,12787 & 0,10859 \\
\hline \multirow{6}{*}{2} & 1 & $-0,00021$ & $-0,03429$ & $-0,12742$ & $-0,25774$ & 234 & $-0,40214$ & $-0,42916$ & 235 & $-0,40216$ & $-0,42926$ \\
\hline & 1 & 0,00029 & 0,03949 & 0,14679 & 0,22012 & 163 & 0,12789 & 0,09219 & 165 & 36 & 216 \\
\hline & & $-0,00009$ & $-0,01724$ & $-0,06404$ & $-0,14190$ & $-0,21951$ & $-0,26459$ & $-0,29145$ & $-0,21951$ & $-0,26181$ & $-0,29153$ \\
\hline & & 0,00032 & 0,04142 & 0,15381 & 0,28636 & 0,31517 & 0,29184 & 0,27761 & 0,31517 & 0,29181 & 0,27759 \\
\hline & 3 & $-0,00003$ & $-0,00822$ & $-0,03060$ & $-0,06741$ & $-0,11470$ & $-0,15483$ & $-0,17624$ & $-0,11472$ & $-0,15486$ & $-0,17631$ \\
\hline & 3 & 0,00018 & 0,01921 & 0,07103 & 0,22852 & 0,38462 & 0,37245 & 0,39553 & 0,38457 & 0,37241 & 0,39550 \\
\hline \multirow{6}{*}{3} & 1 & $-0,00003$ & $-0,00822$ & $-0,03060$ & $-0,06741$ & $-0,11470$ & $-0,15483$ & $-0,17625$ & $-0,11472$ & 486 & $-0,17631$ \\
\hline & & 0,00009 & & 997 & 0,20041 & 084 & 647 & 0,38533 & 124 & & 447 \\
\hline & 2 & $-0,00001$ & $-0,00320$ & $-0,01190$ & $-0,02621$ & $-0,04462$ & $-0,06510$ & $-0,08113$ & $-0,04459$ & $-0,06511$ & 8126 \\
\hline & & 0,00008 & 0,02353 & 0,08755 & 0,19287 & 0,32818 & 0,43811 & 0,49166 & 0,32824 & 18 & 0,49176 \\
\hline & 3 & 0,00000 & 0,00000 & 0,00000 & 0,00000 & 0,00000 & 0,00000 & 0,00000 & 0,00000 & 0,00000 & 0,00000 \\
\hline & & 0,00006 & 0,01712 & 0,06370 & 0,14035 & 0,23910 & 0,39584 & 0,55606 & 0,23861 & 0,39599 & 0,55765 \\
\hline
\end{tabular}


Table 6. Annular plate analysis problem (example 3): plastic multipliers $\lambda^{*}$.

\begin{tabular}{|c|c|c|c|c|c|c|c|c|c|c|c|}
\hline \multirow{3}{*}{ 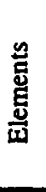 } & \multirow{3}{*}{$\frac{4}{8}$} & \multicolumn{7}{|c|}{ Incremental analysis problem $(70)-(72): \lambda^{* v}$ at the end of each stage $v=1,2, \ldots, 7$} & \multicolumn{3}{|c|}{$\begin{array}{l}\text { Analysis problem }(10)-(14) \text { : } \\
\text { optimal solution } \lambda^{*}\end{array}$} \\
\hline & & 1 & 2 & 3 & 4 & 5 & 6 & 7 & & & \\
\hline & & $\begin{array}{c}q=2,740 \\
M=0,0\end{array}$ & $\begin{array}{c}q=3,276 \\
M=0,0\end{array}$ & $\begin{array}{c}q=3,815 \\
M=0,0\end{array}$ & $\begin{array}{c}q=4,355 \\
M=0,0\end{array}$ & $\begin{array}{c}q=4,355 \\
M=0,1\end{array}$ & $\begin{array}{l}q=4,355 \\
M=0,15\end{array}$ & $\begin{array}{l}q=4,355 \\
M=0,176\end{array}$ & $\begin{array}{l}q=4,355 \\
M=0,1\end{array}$ & $\begin{array}{l}q=4,355 \\
M=0,15\end{array}$ & $\begin{aligned} q & =4,355 \\
M & =0,176\end{aligned}$ \\
\hline \multirow{3}{*}{1} & 1 & 0,0035 & 0,5852 & 1,9089 & 3,9107 & 6,1804 & 8,2989 & 23,4420 & 6,1810 & 8,3010 & 23,5500 \\
\hline & 2 & & & & & & & & & & \\
\hline & 3 & & & 0,4869 & 1,3549 & 2,2712 & 3,1349 & 9,5419 & 2,2713 & 3,1355 & 9,5870 \\
\hline \multirow{3}{*}{2} & 1 & & & & 0,2292 & 0,5051 & 0,3936 & & 0,5049 & 0,3934 & \\
\hline & 2 & & & & & 0,7796 & 2,4158 & 15,4320 & 0,7801 & 2,4175 & 15,5220 \\
\hline & 3 & & & & & & & 0,4437 & & & 0,4488 \\
\hline \multirow{3}{*}{3} & 1 & & & & & & 0,2316 & & & 0,2319 & \\
\hline & 2 & & & & & & & 10,9700 & & & 11,0510 \\
\hline & 3 & & & & & & & & & & \\
\hline
\end{tabular}

Table 7. Annular plate analysis problem (example 3): plastic strains $\Theta_{p}^{*}$.

\begin{tabular}{|c|c|c|c|c|c|c|c|c|c|c|c|}
\hline \multirow{3}{*}{ 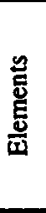 } & \multirow{3}{*}{$\frac{8}{8}$} & \multicolumn{7}{|c|}{$\begin{array}{l}\text { Incremental analysis problem }(70)-(72): \Theta_{p}^{* v} \text { at the end of each stage } \\
v=1,2, \ldots, 7\end{array}$} & \multicolumn{3}{|c|}{$\begin{array}{l}\text { Analysis problem }(10)-(14) \text { : } \\
\text { optimal solution } \theta_{p}^{*}\end{array}$} \\
\hline & & 1 & 2 & 3 & 4 & 5 & 6 & 7 & & & \\
\hline & & $\begin{array}{c}q=2,740 \\
M=0,0\end{array}$ & $\begin{array}{c}q=3,276 \\
M=0,0\end{array}$ & $\begin{array}{c}q=3,815 \\
M=0,0\end{array}$ & $\begin{array}{c}q=4,355 \\
M=0,0\end{array}$ & $\begin{array}{c}q=4,355 \\
M=0,1\end{array}$ & $\begin{array}{l}q=4,355 \\
M=0,15\end{array}$ & $\begin{array}{c}q=4,355 \\
M=0,176\end{array}$ & $\begin{array}{l}q=4,355 \\
M=0,1\end{array}$ & $\begin{array}{l}q=4,355 \\
M=0,15\end{array}$ & $\begin{aligned} q & =4,355 \\
M & =0,176\end{aligned}$ \\
\hline \multirow{6}{*}{1} & \multirow{2}{*}{1} & $-0,00352$ & $-0,58524$ & $-1,90880$ & $-3,91050$ & $-7,08460$ & $-10,0960$ & $-29,3680$ & $-7,0851$ & $-10,0980$ & $-29,5040$ \\
\hline & & 0,00704 & 1,17050 & 3,81760 & 7,82100 & 12,31500 & 16,45800 & 46,3330 & 12,3160 & 16,4610 & 46,5480 \\
\hline & \multirow{2}{*}{2} & & & & & & & & & & \\
\hline & & & & & & & & & & & \\
\hline & \multirow{2}{*}{3} & & & $-0,20905$ & $-0,73076$ & $-1,64240$ & $-2,55630$ & $-8,24640$ & $-1,6425$ & $-2,5569$ & $-8,2866$ \\
\hline & & & & 0,92821 & 2,62520 & 4,48880 & 6,23590 & 19,0250 & 4,4891 & 6,2372 & 19,1170 \\
\hline \multirow{6}{*}{2} & \multirow{2}{*}{1} & & & & $-0,12362$ & $-3,65230$ & $-0,32094$ & & $-0,36511$ & $-0,32081$ & \\
\hline & & & & & 0,44407 & 0,99820 & 0,78288 & & 0,99788 & 0,78256 & \\
\hline & \multirow{2}{*}{2} & & & & & $-0,45299$ & $-1,60200$ & $-10,9670$ & $-0,45329$ & $-1,60320$ & $-11,0330$ \\
\hline & & & & & & 1,51840 & 4,748500 & 30,4670 & 1,519400 & 4,75170 & 30,6460 \\
\hline & \multirow{2}{*}{3} & & & & & & & $-0,31299$ & & & $-0,31667$ \\
\hline & & & & & & & & 0,87548 & & & 0,88567 \\
\hline \multirow{6}{*}{3} & \multirow{2}{*}{1} & & & & & & $-0,15484$ & & & $-0,15505$ & \\
\hline & & & & & & & 0,45542 & & & 0,456020 & \\
\hline & \multirow{2}{*}{2} & & & & & & & $-8,92320$ & & & $-8,98170$ \\
\hline & & & & & & & & 21,82000 & & & 21,9800 \\
\hline & \multirow{2}{*}{3} & & & & & & & & & & \\
\hline & & & & & & & & & & & \\
\hline
\end{tabular}

second element maximal value of plastic multiplier is $\lambda_{21}^{* 5}=0,5051$ (Table 6, marked box), unloading starts, as $\Delta \lambda_{21}^{6}=\lambda_{21}^{6}-\lambda_{21}^{5}=0,3936-0,5051=-0,1115<0$. It is obvious that the precision of solution depends on duration of loading stages $v$. Determination of that fact is the main result of the method proposed in this paper. In Table 6 presented magnitudes of plastic multipliers were obtained from analysis problem (10)-(14) solution for fixed $q$ and $M$ values (three last columns of Table 6). If problem (10)-(14) was solved only for that case, when $q=4,355$ and $M=0,15$, then it would not be possible to identify unloading phenomenon only ac- cording $\lambda_{21}^{*}=0,3934$ magnitude. It once more confirms the necessity of incremental analysis when shakedown process is considered. But both models - (10)-(14) and (70)-(72) - do not simulate actual deformation process when unloading phenomenon appeared in the structure: the results of incremental analysis at the 6th and 7 th stages are obtained neglecting Haar-Kármán principle. Solution results of mathematical model (70)-(72) correspond to system work without unloading phenomenon. Plastic strains $\Theta_{p}^{* v}$ (or $\Theta_{p}^{*}$ ) of annular plate are calculated applying formula (18) and shown in Table 7 , residual displacements $\mathbf{u}_{r}^{* v}$ (or $\mathbf{u}_{r}^{*}$ ) - in Table 8 . 
Table 8. Annular plate analysis problem (example 3): residual displacements $\mathbf{u}_{r}^{* v}$.

\begin{tabular}{|c|c|c|c|c|c|c|c|c|c|c|}
\hline \multirow{3}{*}{$\mathrm{N}^{2}$} & \multicolumn{7}{|c|}{ Incremental analysis problem (70)-(72): $u_{r}^{* v}$ at the end of each stage $v=1,2, \ldots, 7$} & \multicolumn{3}{|c|}{$\begin{array}{l}\text { Analysis problem }(10)-(14) \text { : } \\
\text { optimal solution } \mathbf{u}_{r}^{*}\end{array}$} \\
\hline & 1 & 2 & 3 & 4 & 5 & 6 & 7 & & & \\
\hline & $\begin{array}{c}q=2,740 \\
M=0,0\end{array}$ & $\begin{array}{c}q=3,276 \\
M=0,0\end{array}$ & $\begin{array}{c}q=3,815 \\
M=0,0\end{array}$ & $\begin{array}{c}q=4,355 \\
M=0,0\end{array}$ & $\begin{array}{c}q=4,355 \\
M=0,1\end{array}$ & $\begin{array}{l}q=4,355 \\
M=0,15\end{array}$ & $\begin{aligned} q & =4,355 \\
M & =0,176\end{aligned}$ & $\begin{array}{c}q=4,355 \\
M=0,1\end{array}$ & $\begin{array}{l}q=4,355 \\
M=0,15\end{array}$ & $\begin{aligned} q & =4,355 \\
M & =0,176\end{aligned}$ \\
\hline 1 & $-0,00413$ & $-0,68660$ & $-2,19030$ & $-4,55310$ & $-8,26270$ & $-11,9897$ & $-39,0417$ & $-8,25700$ & $-11,9860$ & $-39,2280$ \\
\hline 2 & 0,00194 & 0,32184 & 1.15497 & 2,50937 & 4,20407 & 5,92777 & 20,36977 & 4,20440 & 5,92910 & 20,4750 \\
\hline 3 & 0,00098 & 0,16267 & 0,57841 & 1,28481 & 2,25936 & 3,32086 & $.13,00616$ & 2,25960 & 3,32180 & 13,0770 \\
\hline 4 & 0,00126 & 0,20905 & 0,77951 & 1,70917 & 2,84457 & 3,99087 & 13,72197 & 2,84470 & 3,99170 & 13,7930 \\
\hline 5 & $-0,00216$ & $-0,35951$ & 0 & $-2,9$ & $-4,91290$ & 20 & $-24,5112$ & $-4,9$ & $-6,98$ & $-24,6380$ \\
\hline 6 & 0088 & 4544 & 0,54038 & 1,19492 & 2,02389 & 2,88750 & 10,5807 & 2,02410 & 2,88820 & 10,6370 \\
\hline 7 & 0,00088 & 0,14557 & 0,54085 & 1,14535 & 1,97783 & 3,00623 & 11,85463 & 1,97810 & 3,00710 & 11,9180 \\
\hline 8 & 0,00037 & 0,06161 & 0,22891 & 0,53743 & 0,89203 & 1,16711 & 3,88181 & 0,89207 & 1,16730 & 3,9026 \\
\hline 9 & $-0,00159$ & 26355 & 97923 & $-2,15473$ & $-3,66743$ & $-5,27783$ & $-19,9378$ & $-3,66780$ & $-5,27920$ & $-20,0440$ \\
\hline 10 & 039 & 7 & 0,24176 & 0,53197 & 0,90 & 1,30641 & 4,89431 & 550 & 1,30670 & 4,9206 \\
\hline 11 & 0,00039 & 6504 & 0,24165 & 0,53172 & 0,90500 & 1,25884 & 5,82754 & 0,90508 & 1,25910 & 5,8607 \\
\hline 12 & $-0,00001$ & $-0,00123$ & $-0,00456$ & $-0,01003$ & $-0,01707$ & 0,01095 & $-0,80697$ & $-0,01707$ & 0,01099 & $-0,81265$ \\
\hline 13 & $-0,00139$ & $-0,23050$ & $-0,85642$ & $-1,88452$ & $-3,20752$ & $-4,61752$ & $-17,4695$ & \begin{tabular}{|l|}
$-3,20770$ \\
\end{tabular} & 4,61860 & $-17,5640$ \\
\hline
\end{tabular}

Physical meaning of residual displacement vector $\mathbf{u}_{r}$ components can be detected from dual relations between equilibrium and geometric equations. However, in the 6th and 7th stages $\Theta_{p}$ and $\mathbf{u}_{r}$ they correspond to system work without an unloading phenomenon.

\section{Conclusions}

Dual mathematical programming problems simulate the actual behaviour of structure at shakedown only when there is not any unloading phenomenon in the structure cross-sections. Rozen optimality criterion (Kuhn-Tucker conditions) ensures compatibility of residual strains and allows plastic strain and residual displacement increment calculation without dual problem solution. Only due to incremental analysis it is possible to fixe the appearance of unloading phenomenon at structure cross-section during shakedown. The proposed technique allows the determination of unloading phenomenon just in one (the first) structure cross-section and it cannot be applied for simulating the actual plastic deformation.

\section{References}

1. Borkowski, A.; Atkočiūnas, J. Optimal design for cyclic loading. In: IUTAM, Symposium on optimization in structural design. Held in Warsaw on August 21-24, 1973. Berlin: Springer Verlag, 1975, p. 432-440.

2. Dorosz, S.; König, J. A.; Sawczuk, A.; Kowal, Z.; Seidel, W. Deflections of elastic-plastic hyperstatic beams under cyelic loading. Archives of Mechanics. Warsaw: 1981, Vol 33, No 5, p. 611-624.

3. Rozvany, G. I. N. Optimal design of flexural systems. Oxford: Pergamon press, 1976. 200 p.

4. Ponter, A. R. S. An upper bound to the small displacements of elastic perfectly plastic structures. Journal of Applied Mechanics, 1972, Vol 39, p. 959-963.

5. Capurso, M.; Corradi, L.; Maier, G. Bounds on deforma- tions and displacements in shakedown theory. In: Proc. materiaux et structures-sous chargement cyclique, Palaiseau: France, 1978, p. 213-244.

6. Polizzoto, C. Upper bounds on plastic strains for elasticperfectly plastic solids subjected to variable loads. International Journal of Mechanical Science, New York: Pergamon, 1979, Vol 21, p. 317-327.

7. Kaneko, L.; Maier, G. Optimum design of plastic structures under displacement's constraints. Computer Methods in Applied Mechanics and Engineering, 1981, Vol 27, Amsterdam: Elsevier, p. 369-392.

8. Cyras, A. Extremum principles and optimization problems for linearly strain hardening elastoplastic structures. Applied mechanics (Прикладная механика), 22, 4. 1986, p. 89-96 (in Russian).

9. Atkočiūnas, J. Design of elastoplastic systems under repeated loading (Расчет упругопластических систем при повторных нагружениях). Vilnius: Science and encyclopaedic publishing house, 1994. 148 p. (in Russian).

10. Kaliszky, S.; Lógó, J. Plastic behaviour and stability constraints in shakedown analysis and optimal design. Structural and Multidisciplinary Optimization, 2002, Vol 24, Berlin, Heidelberg, New York: Springer, p. 118-124.

11. Lange-Hansen, P. Comparative study of upper bound methods for the calculation of residual deformation after shakedown. Technical University of Denmark, Dept. of Struct Engineering and Materials, Series R, 1998, No 49.

12. Mróz, Z.; Weichert, D.; Dorosz, S. (eds.) Inelastic behavior of structures under variable loads. Dordrecht: Kluwer Academic Publishers, 1995. 516 p.

13. Atkočiūnas, J.; Borkowski, A.; König, J. A. Improved bounds for displacements at shakedown. Methods in Applied Mechanics and Engineering, 1981, Vol 28, Amsterdam: Elsevier, p. 365-376.

14. Atkočiūnas, J. Mathematical models of optimization problems at shakedown. Mechanics Research Communications, 1999, Vol 26, No 3, p. 319-326.

15. Casciaro, R.; Garcea, G. An iterative method for shakedown analysis. Computer Methods in Applied Mechanics 
and Engineering, 2002, Vol 191, New York: Pergamon, p. 5761-5792.

16. Koiter, W. T. General theorems for elastic-plastic solids. In: Sheddon, I. N; Hills, R. (eds.) Progress in Solid Mechanics, Amsterdam: North Holland, 1960, p. 165-221.

17. Jarmolajeva, E.; Atkočiūnas, J. Shakedown loading optimization under constrained residual displacements - formulation and solution for circular plates. Journal of Civil Engineering and Management, 2002, Vol VIII, No 1, Vilnius: Technika, p. 54-67.

18. Bazaraa, M. S.; Shetty, C. M. Nonlinear programming theory and algorithms. New York, Chichester, Brisbane, Toronto: John Willey, 1993. 652 p.

19. Belytschko, T. Plane stress shakedown analysis by finite elements. Journal of Mechanical Science, 1972, Vol 14. New York: Pergamon, p. 619-625.

20. Kalanta, S. The equilibrium finite elements in computation of elastic structures. Civil Engineering (Statyba), 1995, No 1, Vilnius: Technika, p. 25-47 (in Russian).

21. König, J. A.; Kleiber, M. On a new method of shakedown analysis. Bulletin de l'academie Polonaise des Sciences. Série des sciences techniques, 1978, Vol XXVI, No 4, p. $167-171$.
22. König, J. A. Shakedown of elastic-plastic structures. Amsterdam: Elsevier Science, 1987. 214 p.

23. Chraptovič, E.; Atkoxiūnas, J. Mathematical programming applications peculiarities in shakedown problem. Civil Engineering (Statyba), 2001, Vol VII, No 2. Vilnius: Technika, p. 106-114 (in Russian).

24. Gutkowski, W.; Bauer, J.; Ivanov, Z. Explicit formulation of Kuhn-Tucker necessary conditions in structural optimization. Computer and Structures, 1990, Vol 37, No 5, New York: Pergamon, p. 753-758.

25. Atkočiūnas, J.; Merkevičiūtè, D. Kuhn-Tucker conditions and load optimization problem at shakedown. In: Proc. of $15^{\text {th }}$ intern. conference on computer methods in mechanics; held on June 3-6. The material of conference reports. Gliwice/Wisla, 2003, p. 59-60.

26. Kalanta S. Elastic plates and shells. In: Computer-aided calculation of structural mechanics problems (Statybinès mechanikos uždaviniu sprendimas kompiuteriais). Vilnius: Science and encyclopaedic publishing house, 1994, p. 163-218 (in Lithuanian).

27. Vainberg, D. V.; Vainberg, E. D. Computation of plates (Расчет пластинок). Kijev: Budivelnik, 1970. 436 p. (in Russian). 